\title{
Durability of solar reflector materials for secondary concentrators used in CSP systems
}

\author{
Aránzazu Fernández-García ${ }^{\text {a,*, }}$ M.Elena Cantos-Soto ${ }^{a}$, Marc Röger ${ }^{\text {b }}$, Christian Wieckert ${ }^{\mathrm{c}}$, \\ Christian Hutter ${ }^{\mathrm{c}}$, Lucía Martínez-Arcos ${ }^{\mathrm{a}}$ \\ a CIEMAT-Plataforma Solar de Almería, Ctra. Senés, km 4, P.O. Box 22, 04200 Tabernas, Almería, Spain \\ ${ }^{\mathrm{b}}$ DLR German Aerospace Center, Institute of Solar Research, Plataforma Solar de Almería, Ctra. Senés, km 4, P.O. Box 39,04200 Tabernas, Almería, Spain \\ ${ }^{\mathrm{c}}$ Paul Scherrer Institute, $\mathrm{CH}-5232$ Villigen PSI, Switzerland
}

\section{A R T I C L E I N F O}

\section{Article history:}

Received 14 March 2014

Received in revised form

29 May 2014

Accepted 17 June 2014

\section{Keywords:}

CSP systems

Central towers

Fresnel collectors

Secondary concentrators

Solar reflector materials

Durability

\begin{abstract}
A B S T R A C T
Secondary concentrators are used in solar concentrating systems to redirect solar beams reflected by the primary concentrators to the focal point or line. These components allow to increase the concentrated solar flux density and hence to lower thermal radiation losses. Solar reflectors for secondary concentrators are permanently exposed to environmental conditions, high radiation fluxes and elevated temperatures that potentially cause stress and degradation throughout the time. Therefore, analyzing solar reflectors of secondary concentrators by simulating these conditions is crucial. No previous research works about the durability of solar reflector materials for secondary concentrators have been reported. The present work is focused on studying the degradation of the reflector materials by simulating accelerated aging, caused by several ambient parameters and the effect of concentrated radiation. Both cooled and uncooled systems for secondary concentrators are included in this study. According to results obtained, aluminum reflectors and thin silvered-glass reflectors glued to an aluminum structure showed minimum reflectance losses and structural degradation under the operation conditions of cooled 3D secondary concentrators (tower systems). Following critical aspects to avoid reflector degradation were identified: to select a suitable adhesive material to glue the thin silvered-glass reflector to the support aluminum structure, to properly protect reflectors edges, to design a suitable cooling system and to avoid the combination of high radiation fluxes with mechanical stress. In addition, laminated silvered-glass reflectors have shown to be suitable for uncooled 2D secondary concentrators (Fresnel collectors). Furthermore, a comparison with naturally aged secondary concentrators using silvered-glass reflectors glued to an aluminum structure revealed that the simulated degradation under accelerated conditions performed in this work did reproduce the most frequent degradation patterns suffered in real operating conditions.
\end{abstract}

(c) 2014 Elsevier B.V. All rights reserved.

\section{Introduction}

Solar energy can be collected to produce electricity through a thermal process by concentrating direct solar radiation with solar concentrating technologies $[1,2]$. Thermal energy collected with solar concentrating devices can also be utilized for industrial process heat, low-temperature heat demand with high consumption rates (domestic hot water, space heating and swimming-pool heating), heat-

\footnotetext{
* Corresponding author. Tel.: + 34950387 800; fax: + 34950365015.

E-mail addresses: arantxa.fernandez@psa.es,

arantxa.fernandez@gmail.com (A. Fernández-García),

melenacant@gmail.com (M.Elen. Cantos-Soto), marc.roeger@dlr.de (M. Röger),

christian.wieckert@psi.ch (C. Wieckert), christian.hutter@lonza.com (C. Hutter),

lucia.martinez@psa.es (L. Martínez-Arcos).
}

driven refrigeration and cooling, and water desalination and purification [3] as well as for the production of solar fuels [4].

In the last decades an increasing number of concentrated solar power (CSP) plants have been built and a further strong increase of this renewable electricity production path is predicted [5]. Two systems are primarily used:

(1) Single axis tracking technologies (2D-concentration). They are based on line-focus concentrating systems in which relatively long primary reflectors are tracked about a single axis to keep the sun's image in focus on a linear absorber or receiver. In the receiver, the solar light is concentrated increasing the enthalpy of an inner circulating heat transfer fluid. After the collection, the heat is converted into electricity by a thermodynamic cycle or stored in a heat storage system for later use. Typical 


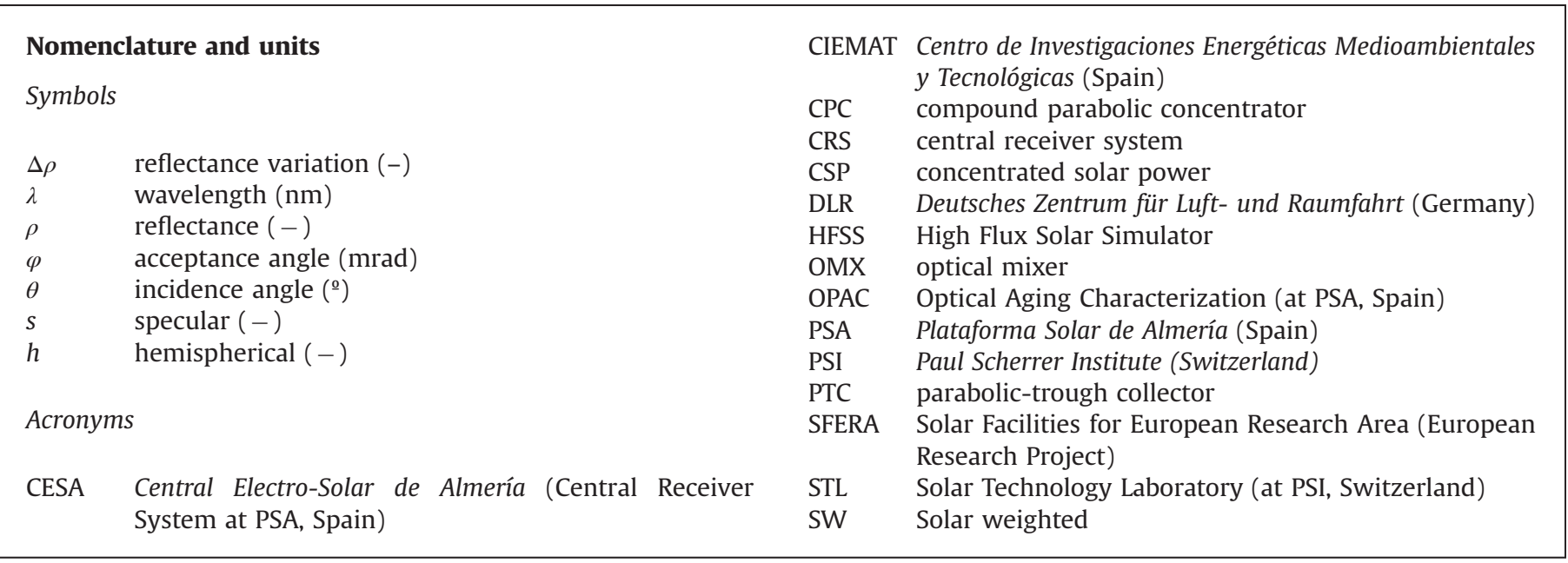

examples are parabolic-trough collectors (PTC) (see Fig. 1 left) and Fresnel collectors (see Fig. 1 right).

(2) Two axis tracking technologies (3D-concentration). Here the process is similar to the single axis one. The peculiarity is that, the focus is a point instead of a line. Representative examples are central receiver systems (CRS), also called central towers, using heliostats reflectors (see Fig. 2 left) or parabolic dishes, typically used with a Stirling engine (see Fig. 2 right).

The practically realized concentration of these systems is up to about 50 times for 2D-concentration and 800 times for 3Dconcentration. Operation temperatures of about $400{ }^{\circ} \mathrm{C}$ for $2 \mathrm{D}$ concentration systems and $800^{\circ} \mathrm{C}$ for 3D-concentration systems are reached. Still higher operation temperatures are advantageous, since they would allow reaching higher electricity production efficiencies. Furthermore, for many processes aiming the production of solar fuels like hydrogen or synthesis gas, temperatures far above $800{ }^{\circ} \mathrm{C}$ are required $[4,6]$.

To achieve such raised temperatures, higher concentrations are needed, which allows - at the same solar power input - smaller receiver apertures and hence lower thermal radiation losses (the thermal radiation losses are increasing with the forth power of the operation temperature). The targeted increase in concentration can be achieved by adding a further optical component, commonly known as a "secondary concentrator". Mostly used for this are compound parabolic concentrators (CPC), either further concentrating on a line (named 2D-CPC) or on a point (named 3D-CPC) $[7,8]$. Normally, 2D-CPC are used in Fresnel collectors and 3D-CPC are employed in CRS. Moreover, a 3D-CPC is integral part of the specific "beam-down" optical system (see Fig. 3), which allows placing solar receiver/reactors on the ground rather than on the tower, with the concentrated irradiation entering from the top [9-11]. While 2D-CPC systems are not actively cooled, 3D-CPC systems have to be cooled (typically with water), due to the high radiative flux density achieved.

A secondary concentrator is hence a reflector, or solar technology component, which reflects the sunlight coming from a primary concentrator onto the focal point or line. Besides increasing the concentration, secondary concentrators might also be required to concentrate the sunlight into the relatively small receiver areas. They ensure the gathering and redirecting of the solar beams towards the absorber.

One crucial issue is that solar reflectors of secondary concentrators are permanently exposed to environmental conditions (humidity, dust), high radiation fluxes and elevated temperatures that potentially cause stress and degradation throughout the time. For most solar reflectors, exposure during service to sunlight particularly to ultraviolet wavelengths, temperature, and moisture can lead to loss in reflectance. Insufficient cooling of mirror surfaces may lead to destruction of the mirror e.g. by melting.

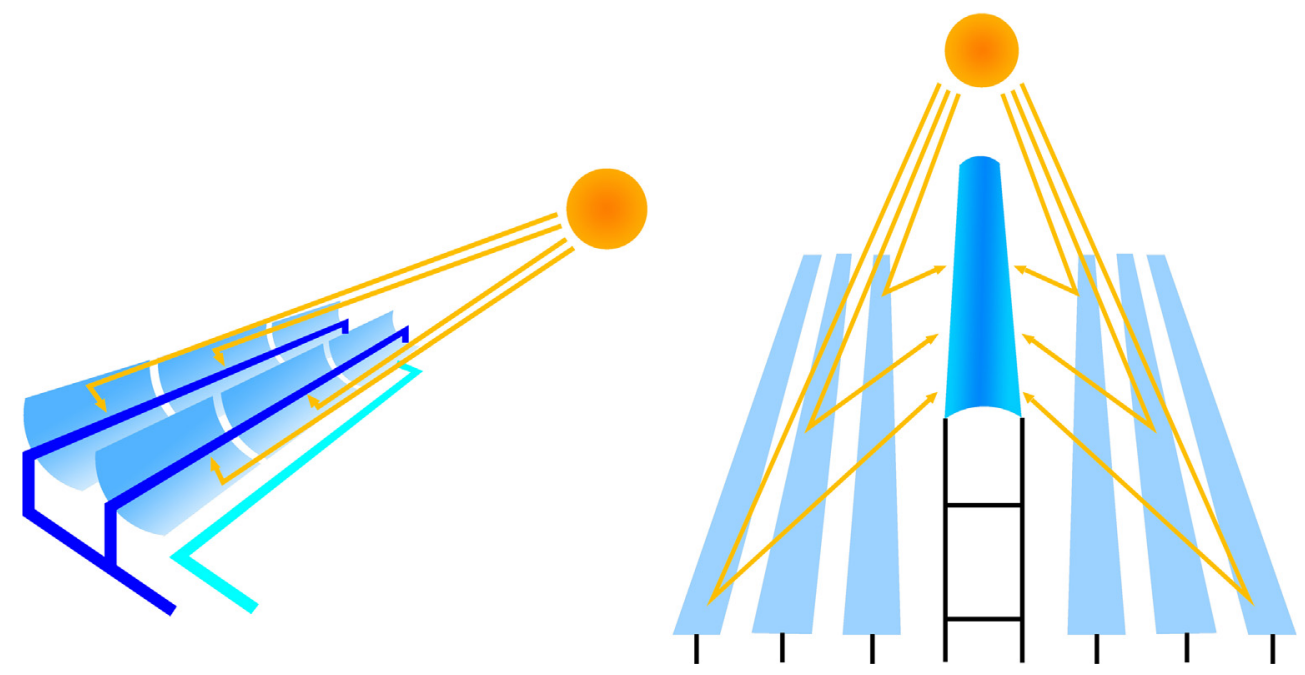

Fig. 1. Diagrams of single axis tracking systems: PTC (left) and Fresnel collector (right). 


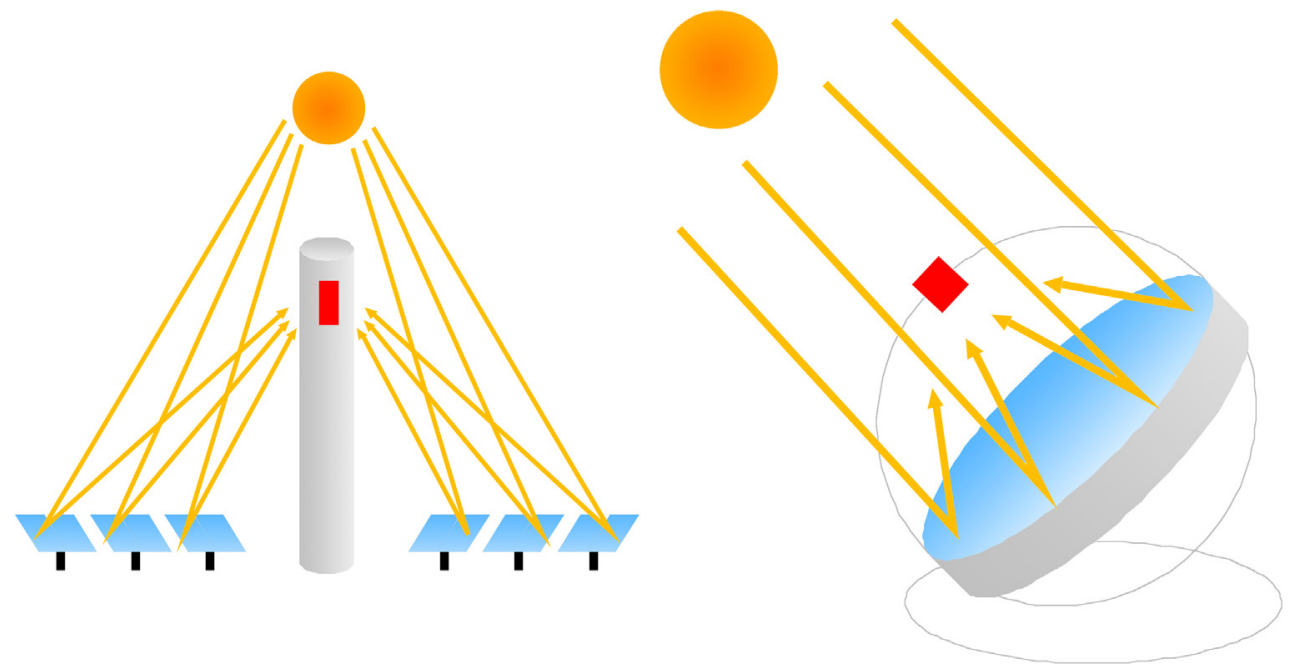

Fig. 2. Diagram of two axis tracking systems: CRS (left) and parabolic dish (right).

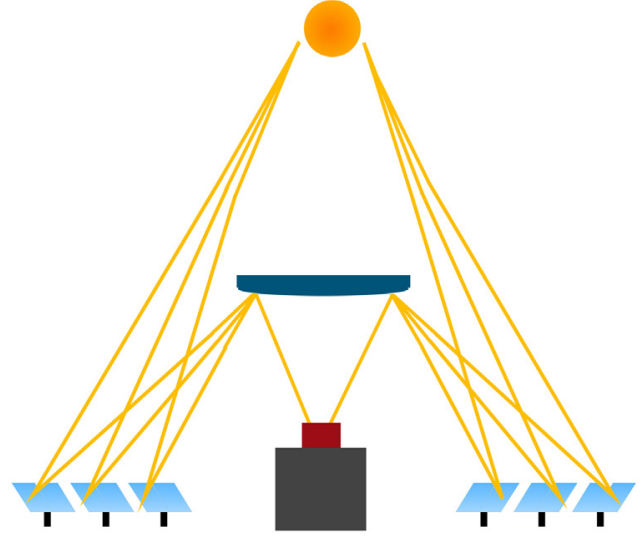

Fig. 3. Diagram of a beam-down system.

Degradation can also result from synergistic effects e.g., photothermal or photohydrolytic [12]. Therefore, analyzing solar reflectors of secondary concentrators by simulating the previous conditions and calculating the reflectance losses produced is essential.

In order to achieve a suitable performance and output of the concentrating solar technology, the maximum reflectance losses admissible in secondary concentrator reflectors depends on several facts, such as the specific application of the solar concentrating plant, the cost of reflector replacements and the effectiveness of the cooling system. Although the ideal expected life time for CSP technology components is from 20 to 25 years, a periodical refurbishment of the secondary concentrators might be carried out without involving a critical financial issue. In this context, 2 to 4 replacements could be reasonably afforded, meaning a secondary life time of 5-10 years. The decision of whether to accomplish this replacement or not, should be taken by considering technical aspects such as the secondary concentrator design. That is, the difficulty and cost of changing the whole secondary concentrator, if it is an indivisible unit, or the possibility of changing divisible concentrator parts, if this is feasible. Although some relevant studies about durability of primary solar reflectors have been published [12,13], no information about the durability of solar reflector materials for secondary concentrators is available in the literature.

The present work is focused on studying the durability of solar reflectors used in secondary concentrators by simulating accelerated exposure caused by several ambient parameters and concentrated radiation. Specific accelerated aging tests were performed under the framework of the Solar Facilities for European Research Area (SFERA) project. The different samples of secondary concentrator sections and reflectors were tested in two locations: weathering tests were completed at the Optical Aging Characterization Laboratory (OPAC) of the Plataforma Solar de Almería (PSA) from Spain, a joint research laboratory which belongs to the Centro de Investigaciones Energéticas Medioambientales y Tecnológicas (CIEMAT) and the German Aerospace Center (Deutsches Zentrum für Luft- und Raumfahrt, DLR), and high flux exposure tests were performed at the Solar Technology Laboratory (STL) of the Paul Scherrer Institute (PSI) in Switzerland. A total of nine selected reflector sample types destined to be employed in cooled and uncooled secondary concentrators, were exposed to different levels of concentrated radiation and accelerated weathering parameters, in order to simulate and analyze the effect caused by the ambient conditions. In addition, a comparison between simulated degradation under accelerated conditions and real aging is included based on a section about natural aging of secondary concentrators by examining the imperfections of the concentrators developed and used in the REFOS $[14,15]$ and SOLGATE $[16]$ research projects.

\section{Materials and methods}

This section includes a description of the tested material types and the methodology followed for both accelerated and natural aging tests.

\subsection{Accelerated aging}

Several types of solar reflectors, designed for cooled and uncooled secondary concentrators, were investigated under accelerated and controlled conditions reproducing those existing in the typical operation of a secondary concentrator, that is high temperature, temperature cycling, high humidity, salty atmosphere and high radiation flux. Two laboratories were involved in the progress of these tests, PSA and PSI.

\subsubsection{Materials}

Two types of samples are included in the study. The first type is proper for secondary concentrators of CRS applications, also called 3D-CPC. In these systems the secondary concentrator has to be cooled (typically with water), due to the high radiative flux density of about $1000 \mathrm{~kW} / \mathrm{m}^{2}$. Maximum temperatures typically achieved by the reflectors in these cooled systems are around $85^{\circ} \mathrm{C}$. 
The second type of samples includes reflector materials suitable for the secondary concentrator of Fresnel collectors or PTC, so-called 2D-CPC. In this case, the radiative flux is much lower and the secondary concentrators are not artificially cooled, reaching temperatures up to around $350{ }^{\circ} \mathrm{C}$. A total number of five manufacturers (named from $\mathrm{A}$ to $\mathrm{E}$ in Table 1 ) provided nine types of samples to be tested. Agreeing to manufacturers' permission, all samples were subjected to the accelerated weathering tests, while high radiation flux tests were applied to samples $1,5,6,7$ and 9, as described in Table 1. The description of the samples tested is shown in Table 1. Five units of each material type were tested at PSA and 3 units of each material type were tested at PSI.

The study of the aluminum material (sample 1 ) is particularly very interesting in this application because the support structure of the secondary concentrators is also typically made of aluminum and, as a consequence, these samples will not suffer mechanical stress due to different dilatation coefficients. In addition, the fact that aluminum samples do not have a glass cover is an asset against breakages. An aluminum reflector diagram can be seen in Fig. 4a. Finally, an aluminum sample can be easily stuck to a support aluminum structure, which is also an advantage. On the other hand, the main disadvantage of this reflector material is that aluminum presents lower initial reflectance than silver.

The rest of the reflectors types for cooled systems included in this study (samples 2-7) are low-iron silvered glass samples, which is the most commonly used type of solar reflector. Samples 2-7 are thin silvered glass reflectors. This type of reflector is the one selected in most of the secondary concentrators manufactured up to now because it can be cut into several pieces to be adapted to the concentrator shape. Typically, reflector edges are not protected after being shaped, before their installation in the secondary concentrator, which means that they have vulnerable segments against possible degradation. Samples from 2 to 4 are only composed by the reflector itself (see Fig. 4b), being the difference in the type of protective paints applied on the back side. It is of main interest to analyze the most durable combination of back paints for the special conditions suffered by secondary concentrators. Samples from 5 to 7 are integrated by a thin silvered glass reflector glued to an aluminum support (see Fig. 4c). The glue applied is the silicone RT $607 \mathrm{~A} / \mathrm{B}$ by Wacker. The goal in this case is to study the final design of the reflector together with the aluminum structure of the concentrator. The difference among these three samples is the protection of the reflector edges.

Finally, samples 8 and 9 are specially designed for uncooled systems and, as a consequence, they are able to withstand higher temperatures (around $350{ }^{\circ} \mathrm{C}$ ). Here, only silver reflectors are regarded because aluminum reflectors are not an optimized solution for such high temperatures. Fig. $4 \mathrm{~d}$ presents the diagram of a thick glass reflector (sample 8 ) and Fig. 4e shows a diagram of a laminated silvered glass reflector (sample 9).

According to the laboratory instruments requirements, the sample size was $8 \times 8 \mathrm{~cm}^{2}$. In the high radiation flux experiment performed at PSI, the water cooled samples were tested in combination with its substrate to simulate and analyze the behavior of the complete system. For this purpose, they were glued on two different structures consisting of water cooled aluminum plates.

\subsubsection{Testing conditions}

The OPAC Laboratory at PSA developed the testing procedure to simulate the aging caused by the extreme weather conditions suffered by reflector materials used in secondary concentrators. This testing was arranged in two main groups: salt spray and combined weathering tests.

Salt spray treatment was applied to both, cooled and uncooled reflectors (see testing conditions in Table 2). CSP plants are often located near the coast. These zones are typically affected by high concentration of salt in the atmosphere. The precipitation of salty compounds onto solar concentrators can severely damage their reflective surface. This damage should be a key factor in the selection of the CSP plant sites and components and it should be considered to avoid unexpected and fast degradation of

Table 1

Samples description.

\begin{tabular}{|c|c|c|c|c|c|}
\hline Type of system & $\begin{array}{l}\text { Sample } \\
\text { code }\end{array}$ & $\begin{array}{l}\text { Manufacturer } \\
\text { code }\end{array}$ & $\begin{array}{l}\text { Thickness }{ }^{\mathrm{C}} \\
\text { (mm) }\end{array}$ & $\begin{array}{l}\text { Reflector } \\
\text { material }\end{array}$ & Sample description \\
\hline \multirow{7}{*}{$\begin{array}{l}\text { Samples for water } \\
\text { cooled systems } \\
\text { (3D CPC) }\end{array}$} & $1^{\mathrm{a}, \mathrm{b}}$ & A & 0.5 & Aluminum & $\begin{array}{l}\text { First surface sample with special lacquer on the front surface. Back side glued to an } \\
\text { aluminum structure for cooling system (at PSI) }\end{array}$ \\
\hline & $2^{a}$ & B & 1.0 & Silver & $\begin{array}{l}\text { Second surface sample with } 1-\mathrm{mm} \text { low-iron glass front cover. Back surface white painted } \\
\text { (type 1). } \\
\text { No protected edges }\end{array}$ \\
\hline & $3^{a}$ & $\mathrm{~B}$ & 1.0 & Silver & $\begin{array}{l}\text { Second surface sample with } 1-\mathrm{mm} \text { low-iron glass front cover. Back surface white painted } \\
\text { (type } 2 \text { ). } \\
\text { No protected edges }\end{array}$ \\
\hline & $4^{a}$ & B & 1.0 & Silver & $\begin{array}{l}\text { Second surface sample with } 1-\mathrm{mm} \text { low-iron glass front cover. Back surface white painted } \\
\text { (type } 3 \text { ). } \\
\text { No protected edges }\end{array}$ \\
\hline & $5^{\mathrm{a}, \mathrm{b}}$ & C & 5.3 & Silver & $\begin{array}{l}\text { Second surface sample with } 1-\mathrm{mm} \text { low-iron glass front cover. Back side glued to an } \\
\text { aluminum structure for cooling system. } \\
\text { No protected edges }\end{array}$ \\
\hline & $6^{\mathrm{a}, \mathrm{b}}$ & C & 5.3 & Silver & $\begin{array}{l}\text { Second surface sample with } 1 \text {-mm low-iron glass front cover. Back side glued to an } \\
\text { aluminum structure for cooling system. } \\
\text { Edge protection type } 1 \text { (semi-gloss temperature resistant paint by Jansen) }\end{array}$ \\
\hline & $7^{\mathrm{a}, \mathrm{b}}$ & $C$ & 5.3 & Silver & $\begin{array}{l}\text { Second surface sample with } 1 \mathrm{~mm} \text { thin low-iron glass front cover. Back side glued to an } \\
\text { aluminum structure for cooling system. } \\
\text { Edge protection type } 2 \text { (universal temperature resistant paint by Jansen) }\end{array}$ \\
\hline \multirow{2}{*}{$\begin{array}{l}\text { Samples for } \\
\text { uncooled systems } \\
(2 D \text { CPC) }\end{array}$} & $8^{a}$ & $\mathrm{D}$ & 3.4 & Silver & $\begin{array}{l}\text { Second surface sample with } 3 \text {-mm low-iron glass front cover. Black painted back surface\# } \\
\text { No protected edges. }\end{array}$ \\
\hline & $9^{\mathrm{a}, \mathrm{b}}$ & $\mathrm{E}$ & 2.0 & Silver & $\begin{array}{l}\text { Second surface sample with } 2-\mathrm{mm} \text { low-iron glass front cover and } 0.5 \mathrm{~mm} \text { low-iron glass } \\
\text { back cover. Edges protected with glass. Specially designed for high temperatures }\end{array}$ \\
\hline
\end{tabular}

\footnotetext{
a Sample tested at PSA.

b Sample tested at PSI.

c Including back structure.
} 
a

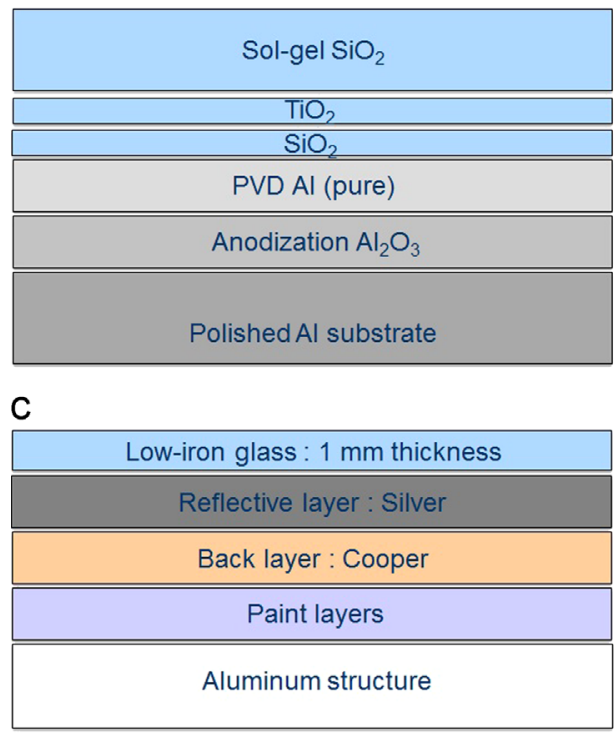

b

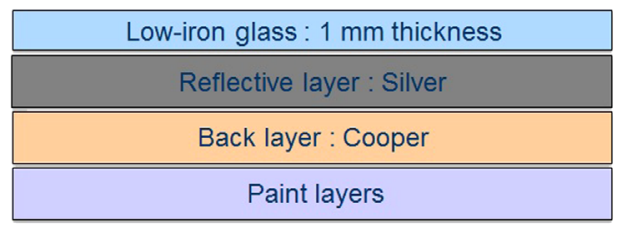

d

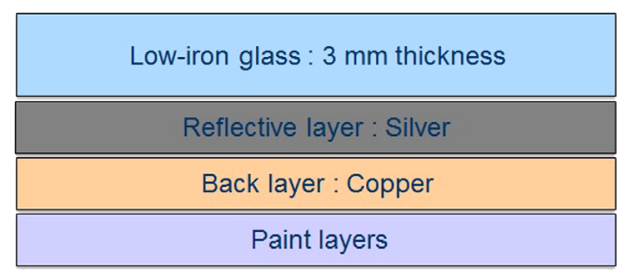

e

Low-iron glass : 2 mm thickness

Reflective layer : Silver

Low-iron glass : $0.5 \mathrm{~mm}$ thickness

Fig. 4. Diagrams of the reflector types: (a) sample 1; (b) samples 2, 3 and 4; (c) samples 5, 6 and 7; (d) sample 8; and (e) sample 9.

Table 2

Salt spray testing conditions (all sample types).

\begin{tabular}{llllll}
\hline Chamber & Standard & Type of test & Temperature $\left({ }^{\circ} \mathbf{C}\right)$ & $\mathbf{p H}$ & Time (h) \\
\hline Salt spray & ISO 9227 [17] & $\begin{array}{l}\text { Neutral salt } \\
\text { spray (NSS) }\end{array}$ & $35 \pm 2$ & $6.5-7.2$ & 480 \\
\hline
\end{tabular}

component materials. In this test, the influence of salty atmospheres on the durability of the different solar reflector materials, under accelerated aging conditions, is studied. This test is also typically applied to primary reflectors.

Combined weathering tests, which involved a sequence of several experiments, were applied separately for cooled (see Table 3) and uncooled samples (see Table 4) because the testing conditions designed were different. The specific order of the combined weathering tests is detailed in these tables. Constant temperature tests reproduce representative temperatures reached under real operating conditions (that is, $+85^{\circ} \mathrm{C}$ for cooled and $+350^{\circ} \mathrm{C}$ for uncooled samples). Thermal cycling tests were performed to simulate the abrupt increases and decreases of temperature in the startup and shutdown tasks experimented during real operation of the plant. Humidity test proves the material resistance against condensed water, naturally produced by rain or dew. Damp heat test, which represents the most aggressive operating conditions, permits to check the durability of the different materials under of humidity and high temperatures. These extreme conditions can occur when the system is operating (so, high temperature takes place) and humidity is simultaneously high (due to high ambient humidity or after water condensation). These tests were consecutively performed to the same samples in order to assess the accumulative effect of the different weather and operating conditions. This way, it is expected that the first two tests produce mechanical alterations in the samples (for example cracks or layering) which could cause or accelerate chemical degradation (mainly corrosion in the reflective layers) provoked by the two final tests that involve significant humidity. Humidity and damp heat tests are also typically applied to primary reflectors, while temperature, temperature cycling and high flux radiation tests were specifically thought for secondary concentrators.

In addition, the STL at PSI developed the high radiation flux test in the High Flux Solar Simulator (HFSS) (see Table 5).

The laboratory equipment employed to simulate the above described aging conditions consisted of:

- Salt spray test chamber, CSF-500 by Control Técnica (Fig. 5). This chamber has been manufactured to perform tests according to ISO 9227 standard [17]. Combined cycles can be programmed (salt spray, condensation and ambient conditions). Different temperatures can also be applied during tests, from 10 to $50{ }^{\circ} \mathrm{C}$.

- Muffle furnace, LT 40/12 by Nabertherm. Constant temperature tests can be done at temperatures up to $1200{ }^{\circ} \mathrm{C}$. Additionally, a special device has been developed by CIEMAT to carry out automatic temperature cycles tests. This device uses a conventional muffle furnace for the heat up cycle and a fan for the cool down cycle. In addition, water can be sprayed in the cool down cycle.

- Weathering chamber, SC340 by ATLAS. Several combinations of humidity and temperature can be applied, both in steady conditions and in cycling combinations. If only temperature testing is done, the temperature range is from -40 to $120^{\circ} \mathrm{C}$. If combined temperature and humidity testing is done, the temperature range is from +10 to $+90{ }^{\circ} \mathrm{C}$ and the humidity range is from 10 to $99 \%$.

- The HFSS consists of 10 water-cooled Xenon arc lamps $\left(15 \mathrm{~kW}_{\mathrm{e}}\right.$ each) [21] (see Fig. 6 left). Its flux distribution is peaked with a width of about $5 \mathrm{~cm}$. For these tests, however, an approximately homogeneous flux distribution over an area of $80 \times 80 \mathrm{~mm}^{2}$, the area of the sample surface, is required. To accomplish this, a new optical mixer (OMX) adapted to the size of the samples was built 
Table 3

Combined weathering testing conditions (cooled samples, 3D-CPC), consecutively applied.

\begin{tabular}{|c|c|c|c|c|c|}
\hline Chamber & Standard & Type of test & Temperature $\left({ }^{\circ} \mathrm{C}\right)$ & Humidity (\%) & Time (h) \\
\hline Muffle furnace & - & Constant temperature & +85 & Ambient & 480 \\
\hline Weathering chamber & IEC 61215 [18] & Thermal cycling & From $-40 \pm 2$ to $+85 \pm 2$ & Ambient & 300 (50 cycles of $6 h)$ \\
\hline Weathering chamber & ISO 6270-2 [19] & Humidity $(\mathrm{CH})$ & $+40 \pm 3$ & 100 & 480 \\
\hline Weathering chamber & ISO 61215 [18] & Damp heat & $+85 \pm 2$ & $85 \pm 5$ & 1000 \\
\hline
\end{tabular}

Table 4

Combined weathering test testing conditions (uncooled samples, 2D-CPC), consecutively applied.

\begin{tabular}{|c|c|c|c|c|c|}
\hline Chamber & Standard & Type of test & Temperature $\left({ }^{\circ} \mathrm{C}\right.$ ) & Humidity (\%) & Time (h) \\
\hline Muffle furnace & - & Constant temperature & +350 & ambient & 480 \\
\hline Muffle furnace & - & Thermal cycling & From ambient to +350 & ambient & $50(50$ cycles of $1 \mathrm{~h})$ \\
\hline Weathering chamber & ISO 6270-2 [19] & Humidity $(\mathrm{CH})$ & $+40 \pm 3$ & 100 & 480 \\
\hline Weathering chamber & ISO 61215 [18] & Damp heat & $+85 \pm 2$ & $85 \pm 5$ & 1000 \\
\hline
\end{tabular}

Table 5

High flux solar exposure testing conditions [20] in the HFSS (for sample codes see Table 1).

\begin{tabular}{|c|c|c|c|}
\hline Type of sample & $\begin{array}{l}\text { Position inside the } \\
\text { solar simulator }\end{array}$ & Average flux levels & Exposure time/cycling \\
\hline Water cooled (3D CPC) samples (codes 1, 5, 6 and 7) & Vertical & $590 ; 980 ; 1470 \mathrm{~kW} / \mathrm{m}^{2}$ & Per flux level: $3 \mathrm{~h} 30^{\prime}$ incl. $3 \times 10^{\prime} \mathrm{ramp} / 15^{\prime}$ cool down \\
\hline Uncooled (2D CPC) sample (code 9) & Vertical & $93 ; 151 ; 253 ; 291 \mathrm{~kW} / \mathrm{m}^{2}$ & Per flux level: $3 \mathrm{~h} 30^{\prime}$ incl. $3 \times 10^{\prime} \mathrm{ramp} / 15^{\prime}$ cool down \\
\hline Water cooled (3D CPC) samples (codes from 5 to 7 ) & $45^{\circ}$ Tilted & $610 ; 980 \mathrm{~kW} / \mathrm{m}^{2}$ & Per flux level: $1 \mathrm{~h} 45^{\prime}$ incl. $2 \times 10^{\prime} \mathrm{ramp} / 15^{\prime}$ cool down \\
\hline
\end{tabular}

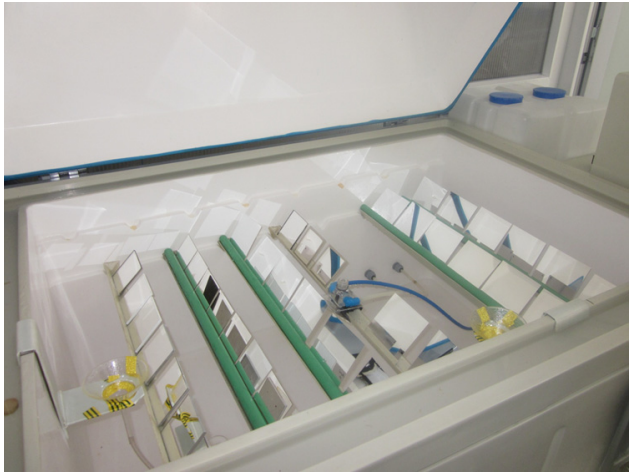

Fig. 5. Salt Spray chamber samples holder at PSA.

and characterized (Fig. 6 right). The OMX is a rectangular tube consisting of mirrored inner walls, leading to an approximate homogenization of the flux at its exit where the samples were placed.

\subsubsection{Experimental evaluation}

The reflectance, $\rho$, as the key parameter for solar reflectors, has been chosen to compare the optical quality of the different materials and also as indicator for the reflector degradation of all samples subjected to accelerated ageing. Reflectance measurements of all samples are taken before any test to establish a ranking among the different materials included in the study. In addition, reflectance measurements of all samples are taken after the experiments to track the reflectance evolution, by calculating the reflectance variation, $\Delta \rho$, that is, the reflectance after the test minus the initial reflectance.

Although there are several ways to express the reflectance, the most relevant optical property in a solar reflector for CSP systems is the solar-weighted (SW) specular reflectance, $\rho_{S}(S W, \theta, \varphi)$, measured at suitable incidence and acceptance angles $(\theta$ and $\varphi$, respectively) [22]. There is no commercial instrument available to measure this parameter. Therefore, $\rho_{s}(S W, \theta, \varphi)$ was approximated using the Eq. (1) [23].

$\rho_{S}(S W, \theta, \varphi)=\frac{\rho_{S}(\lambda, \theta, \varphi)}{\rho_{h}(\lambda, \theta, h)} \cdot \rho_{h}(S W, \theta, h)$

Being $\lambda$ the wavelength, $\rho_{s}(\lambda, \theta, \varphi)$ the monochromatic specular reflectance, $\rho_{h}(S W, \theta, h)$ the SW hemispherical reflectance and $\rho_{h}(\lambda$, $\theta, h)$ the monochromatic hemispherical reflectance. Hemispherical is indicated with $h$ while specular is designated with $s$.

$\rho_{S}(\lambda, \theta, \varphi)$ was measured with the 15R-USB portable specular reflectometer, manufactured by Devices and Services [24]. According to the manufacturer, this instrument has a resolution of 0.001 and a repeatability of \pm 0.002 . It measures in $\theta=15^{\circ}$ and a $\lambda$ range between 635 and $685 \mathrm{~nm}$, with a peak at $\lambda=660 \mathrm{~nm}$. From the four $\varphi$ available, $\varphi=12.5$ mrad was selected because it is the most commonly used acceptance angle to characterize primary reflector materials [22]. Therefore, the proper nomenclature for the results obtained is $\rho_{s}\left(660 \mathrm{~nm}, 15^{\circ}, 12.5 \mathrm{mrad}\right)$. Measurements of this parameter are taken in three different positions (covering the whole sample surface) in every single sample and the average value is considered.

In addition, the spectral hemispherical reflectance is measured with the spectrophotometer model Lambda 1050 manufactured by Perkin-Elmer and a $150-\mathrm{mm}$ diameter integrating-sphere accessory [25]. According to the manufacturer, this instrument has an uncertainty of \pm 0.007 . $\rho$ was measured at $\theta=8^{\circ}$ and over a range representative of the terrestrial solar spectrum, from $250 \mathrm{~nm}$ to $2500 \mathrm{~nm}$, using $5 \mathrm{~nm}$ intervals. In this case, three measurements are realized in every single sample, rotating the reflector by 90 degrees (hence, $0^{\circ}, 90^{\circ}$ and $180^{\circ}$ values are recorded), and the average value is obtained. From these set of values, $\rho_{h}\left(\lambda, 8^{\circ}, \mathrm{h}\right)$ is taken at $\lambda=660 \mathrm{~nm}$ (to be properly compared with the results from the reflectometer) and $\rho_{h}\left(\mathrm{SW}, 8^{\circ}, \mathrm{h}\right)$ is calculated following ISO 

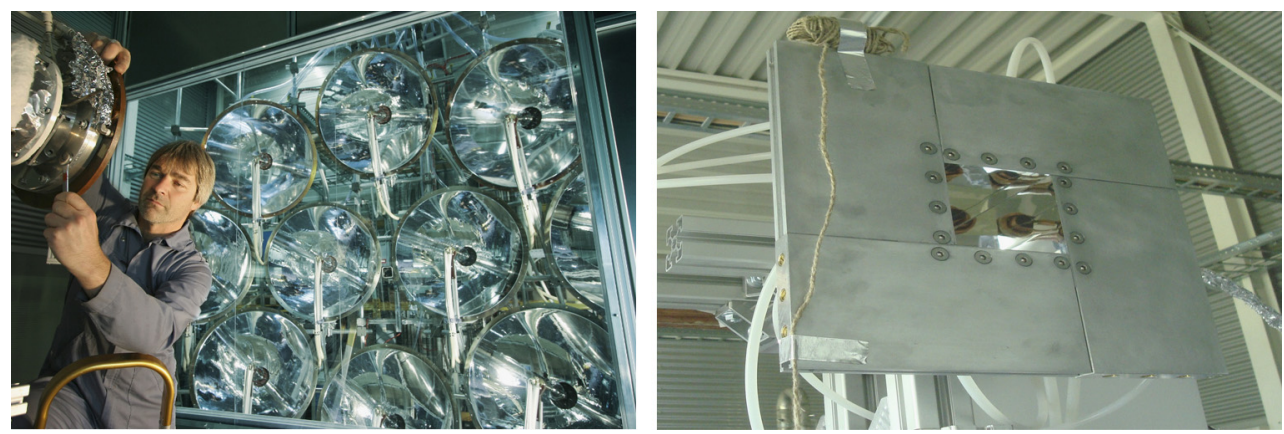

Fig. 6. High flux simulator (left) and frontal view of the OMX (right) at PSI.

Standard 9050 [26] and using solar direct spectrum from ASTM G173-03 [27].

Finally, optical inspection using a Panasonic LUMIX camera, model DMC-F745, and a 3D light microscope, model Axio CSM 700 manufactured by Zeiss [28] is performed to the samples to analyze the possible degradation appearing with the accelerated aging tests.

\subsection{Natural aging}

Natural aging analysis and observation is essential to check how accelerated aging in laboratory correlates to reality. For this purpose, two 3D secondary concentrators, which were exposed to real working conditions on a CRS at the PSA, were visually inspected.

\subsubsection{Materials}

The low and medium temperature secondary concentrators of the REFOS $[14,15]$ and SOLGATE projects [16] were installed in the Central Electrosolar de Almería 1 (CESA-1) central tower at the PSA in about $60 \mathrm{~m}$ height (see Fig. 7 left). The receiver system consisted of three pressurized absorbers, with the corresponding secondary concentrators, named SecNT1, SecNT2 and SecNT3 (see Fig. 7 right). The three absorbers and concentrators were connected in series so the circulating fluid temperature rose from SecNT1 to SecNT3. The secondary concentrators investigated in this paper were the first two in the sense of the fluid flow that is SecNT1 and SecNT2.

The secondary concentrators used in these projects were water-cooled systems. They have a hexagonal entry aperture and an 18-edged exit aperture and are composed by reflector segments (82 in the case of SecNT1 and 96 in the case of SecNT2) of different shapes (triangles, trapeziums, and rectangles). The total reflector area of one secondary is $3.44 \mathrm{~m}^{2}$. A secondary concentrator reflector segment is made of a $0.6-\mathrm{mm}$ thin silvered-glass mirror. These reflectors are bent in one axis and glued to a 3-mm thick aluminum roll bond plate, which is water cooled on the back side to avoid excessive temperatures. Reflector material is similar to the samples 2-7 included in the accelerated aging study and the set of reflector plus cooled aluminum support structure is the same type of the one used in samples 5 to 7.

\subsubsection{Testing conditions}

The secondary concentrators analyzed were installed during 7 years (between 2002 and 2009), whereas their total experimental operation time was around 14 months. The three pressurized absorbers located behind the secondary concentrators operated in series with outlet temperatures of around $550{ }^{\circ} \mathrm{C}$, $800{ }^{\circ} \mathrm{C}$, and $1000^{\circ} \mathrm{C}$, respectively. The secondary concentrators investigated in this paper were the two located in front of the
$550{ }^{\circ} \mathrm{C}$ and $800{ }^{\circ} \mathrm{C}$ receiver module (SecNT1 and SecNT2, respectively). Convective flows of hot air, radiative fluxes caused by thermal emission of the receiver, the high solar fluxes of the heliostat field during the day and possible condensation of humidity during night represent harsh conditions for the secondary concentrator materials.

\subsubsection{Experimental evaluation}

A detailed visual inspection of the two secondary concentrators was performed to observe aging effects under real operating conditions and establish a comparison with the reflector samples tested in laboratory against accelerated aging. Pictures were taken with a Panasonic LUMIX camera, model DMC-F745. No laboratory analysis was performed due to the impossibility to disassembling or cutting appropriate mirror samples from the secondary concentrators without their destruction.

\section{Results and discussion}

This section includes results obtained in the accelerated and natural aging tests performed. In addition, a comparison between both accelerated and natural aging is presented.

\subsection{Accelerated aging}

Average hemispherical reflectance spectra of all material types before being tested, measured with the spectrophotometer, are presented in Fig. 8. This figure shows the typical spectrum of silvered-glass samples (samples from 2 to 9 ) and aluminum with special protection (sample 1). Reflectance spectra of samples 2 to 7 are quite similar, having the spectrum of sample 9 a deeper elbow in the visible range and the spectrum of sample 8 a decrease in the near infrared range. Reflectance spectrum of sample 1 has a valley around $800 \mathrm{~nm}$, as usual for aluminum materials.

Average $\rho_{S}\left(\mathrm{SW}, 15^{\circ}, 12.5 \mathrm{mrad}\right)$ of all samples before testing was obtained by taking measurements with the spectrophotometer and reflectometer, and applying eq. (1) afterwards. Results are presented in Table 6. As can be seen in Table 6, all silvered-glass manufacturers presented $\rho_{S}\left(\mathrm{SW}, 15^{\circ}, 12.5 \mathrm{mrad}\right)$ values between 0.910 and 0.950 . Only reflectance of laminated reflector (sample 9) is lower than for the rest of the silvered-glass reflectors (samples from 2 to 8 ). It is also predictable to have slightly reduced reflectance in thick glass reflector (sample 8) than in thin glass reflector (samples 2 to 7 ) because of absorption inside the glass. The aluminum reflector (sample 1) shows lower initial reflectance than silver reflectors, as expected.

Table 7 presents $\Delta \rho$ results after all accelerated aging tests. In this table, results of the tests that were individually applied (salt spray and high flux) represent the absolute reflectance loss suffered by the samples on them. Conversely, results of the tests 

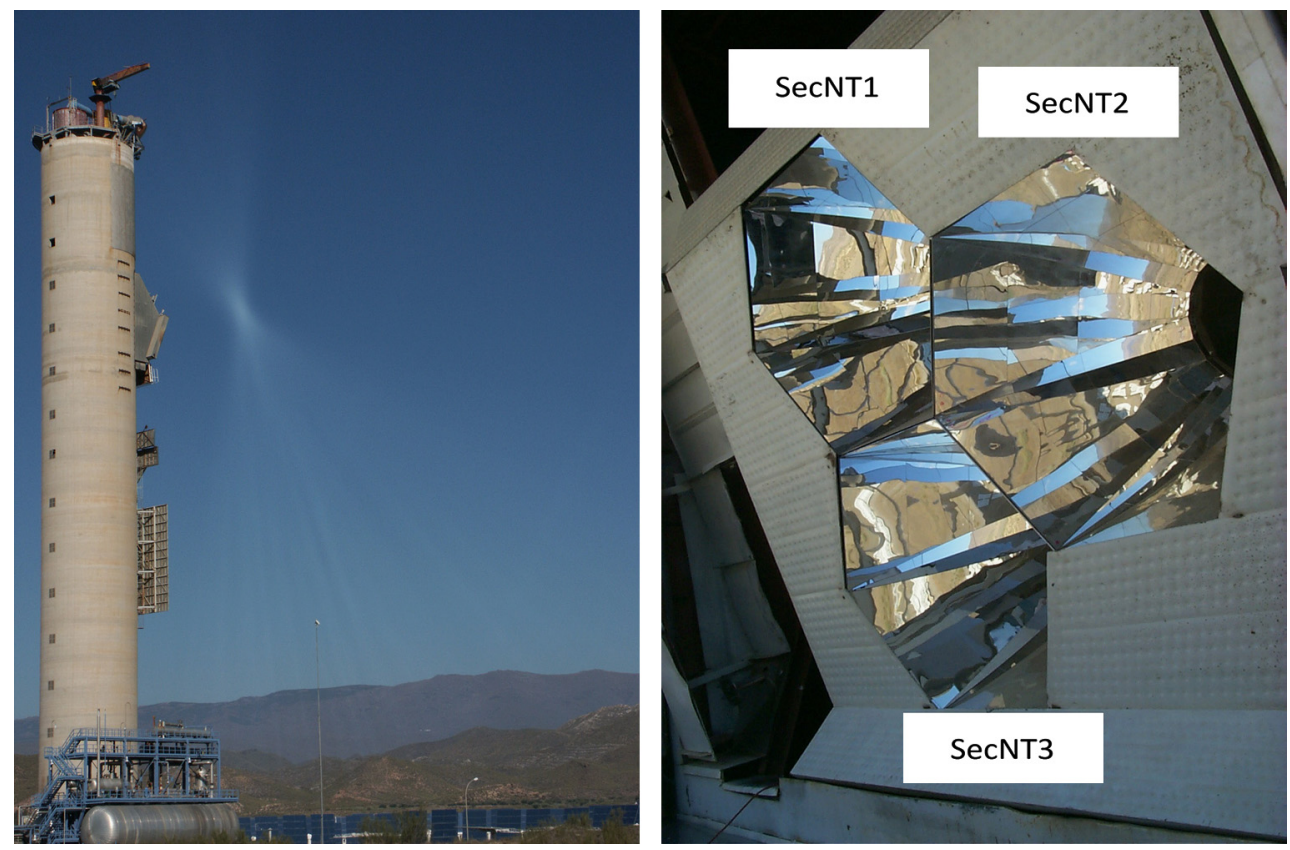

Fig. 7. CESA-1 tower (left) and REFOS secondary concentrator unit composed of three secondary concentrators (right) at PSA

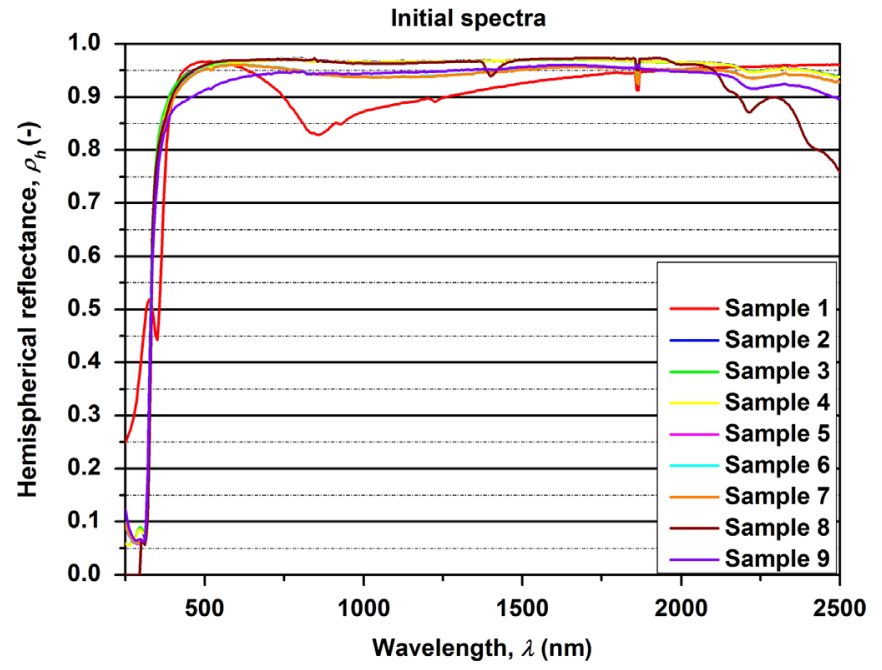

Fig. 8. Initial hemispherical reflectance spectra of all material types.

that were consecutively applied on the samples (constant temperature, temperature cycling, humidity and damp heat) are additive. That is, initial reflectance considered to calculate $\Delta \rho$ in the four tests is the value measured at the beginning of the consecutive tests, not just before each test.

Variations in reflectance around \pm 0.003 can be considered negligible because they are inside the instruments uncertainty. After the tests were performed, the following observations may be made concerning results presented in Table 7 :

(a) In terms of salt spray tests, sample 1 (aluminum) presented the highest decrease in reflectance. However, this reflectance loss is not as high to be considered critical. Concerning the rest of the silver based samples, there was no significant reflectance loss in this test.

(b) Concerning combined weathering tests, aluminum reflector (sample 1) had the best behavior for cooled systems ( $\Delta \rho=$ $-0.009) . \Delta \rho$ reached by this sample was -0.005 in the first test (constant temperature). Sample 9 also showed a suitable response $(\Delta \rho=-0.010)$, being this small decrease mainly detected in the constant temperature, without any visible degradation.

Samples 2 and 3 showed the second best response, presenting both a similar behavior, with an average $\Delta \rho$ of -0.010 after constant temperature test, and $\Delta \rho$ around -0.016 after the whole consecutive weathering test campaign. Damp heat test did not affect these samples. According to these results, back paints type 1 and 2 (corresponding to the samples 2 and 3, respectively) appear to be good enough for this type of systems. The only problem in these two samples was degradation in the back paints close to the edges, involving silver corrosion (see Figs. 9-11). This problem should be avoided with a proper edge protection.

Durability of sample 4 was excellent in the first three tests, with a $\Delta \rho$ negligible. Nevertheless, this material suffered a considerable degradation of the back paint and the silver after the damp heat test $(\Delta \rho=-0.110)$, as can be seen in Fig. 12. As a consequence, back paint type 3 can be considered really adequate for all operating conditions, except for the combination of high temperature and humidity (that is, the damp heat test), which represents the most aggressive operating conditions.

Medium to high reflectance losses (between -0.029 and -0.068 ) were noticed in thin-glass samples glued to an aluminum support structure (samples 5, 6 and 7). The increasing degradation throughout the combined weathering tests could be due to a chemical reaction of the glue used between the reflector surface and the aluminum structure. This conclusion was obtained because the corrosion signs appeared exactly in the same places where the glue was applied (as shown in Fig.13 for sample 5). This degradation was less aggressive in sample 6, where protection type 1 was applied on the edges, which indicates that the chemical reaction happened in the glue is aggravated by the penetration of oxygen through the unprotected or insufficiently protected edges. Therefore, this type of protection has demonstrated to be more effective than the other two options tested. The sample without protection in the edges (number 5) presented the worst behavior (as expected). As a result, the conditions applied in the damp heat test seem to be the most aggressive ones. This effect may be noticed in Figs. 13 and 14, where degradation stains are observed 
Table 6

Initial average SW specular reflectance of all type of samples before the tests.

\begin{tabular}{|c|c|c|c|c|c|c|c|c|c|}
\hline Sample code & 1 & 2 & 3 & 4 & 5 & 6 & 7 & 8 & 9 \\
\hline$\rho_{s}(\mathrm{SW}, 15,12.5 \mathrm{mrad})(-)$ & 0.861 & 0.949 & 0.949 & 0.948 & 0.947 & 0.947 & 0.947 & 0.945 & 0.912 \\
\hline
\end{tabular}

Table 7

Reflectance variation results after accelerated aging tests.

\begin{tabular}{|c|c|c|c|c|c|c|c|}
\hline & \multirow[t]{2}{*}{ Sample code } & \multirow[t]{2}{*}{ Salt spray } & \multicolumn{4}{|c|}{ Consecutive weathering tests } & \multirow[t]{2}{*}{ High flux } \\
\hline & & & Constant temperature & Thermal cycling & Humidity & Damp heat & \\
\hline \multirow{7}{*}{ Samples for cooled system (3D CPC) } & 1 & -0.017 & -0.005 & -0.007 & -0.007 & -0.009 & -0.004 \\
\hline & 2 & 0.002 & -0.011 & -0.017 & -0.014 & -0.014 & - \\
\hline & 3 & 0.000 & -0.009 & -0.014 & -0.017 & -0.017 & - \\
\hline & 4 & 0.001 & -0.001 & 0.001 & 0.000 & -0.110 & - \\
\hline & 5 & -0.002 & -0.021 & -0.039 & -0.036 & -0.068 & -0.001 \\
\hline & 6 & 0.000 & -0.019 & -0.016 & -0.027 & -0.029 & -0.001 \\
\hline & 7 & 0.001 & -0.032 & -0.029 & -0.040 & -0.055 & 0.000 \\
\hline \multirow[t]{2}{*}{ Samples for uncooled systems (2D CPC) } & 8 & 0.002 & -0.057 & -0.086 & -0.089 & -0.095 & - \\
\hline & 9 & 0.001 & -0.007 & -0.004 & -0.008 & -0.010 & -0.014 \\
\hline
\end{tabular}

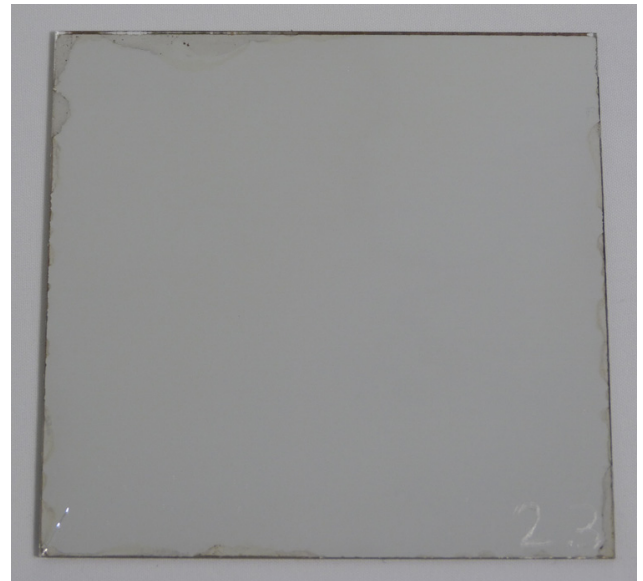

Fig. 9. Picture of sample 2, after the humidity test.

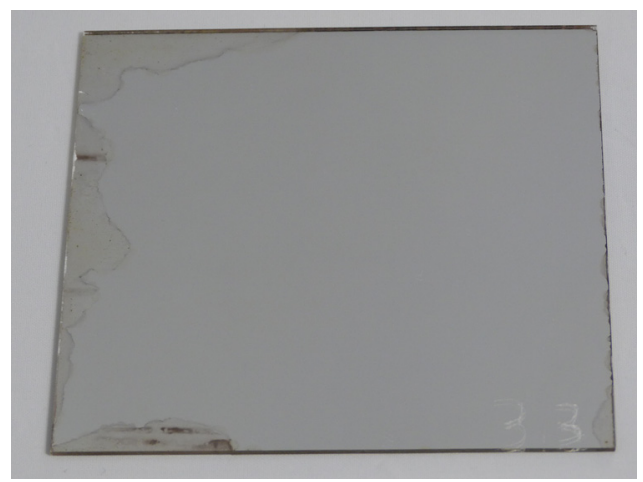

Fig. 10. Picture of sample 3, after the humidity test.

due to a chemical reaction with the glue applied between the sample and the back aluminum support, effect that is also aggravated by the fact that the edges are insufficiently protected. If Figs. 13 and 14 are compared, a more aggressive degradation is noticed after the damp heat test. Fig. 15 provides a microscopic observation on the middle of the sample of these degradation patterns. Sample 7, with protection type 2 applied, showed an intermediate response between samples 5 and 6 . Therefore, protection type 1 behaves better than protection type 2 . These

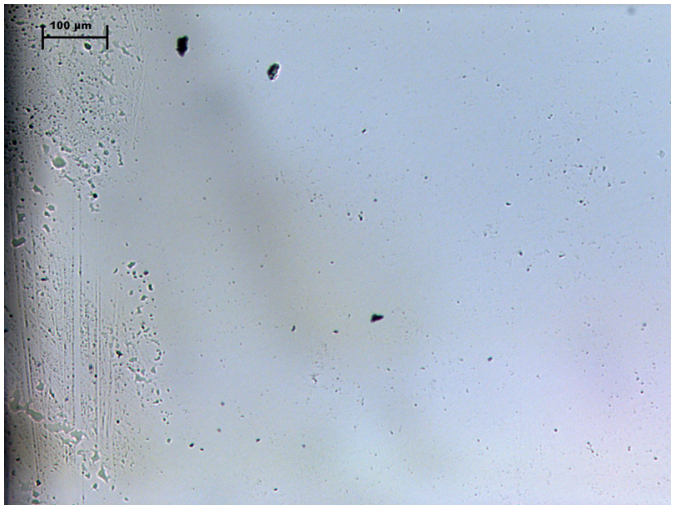

Fig. 11. Microscopic view of sample 3 edge, after the humidity test

results demonstrate the great importance of incorporating an adequate edge protection.

Finally, high reflectance loss $(\Delta \rho=-0.095)$ was observed in the thick silvered-glass reflector for uncooled systems (sample 8), due to corrosion of the silver layer (Fig. 16). This degradation started to appear after the constant temperature test and significantly increased after the thermal cycling test. The reason why the sample 8 appears more degraded might be due to an insufficient protective back layer or due to absence of protection on the edges for such high temperatures reached by the uncooled systems (although the protective back paint does not appeared visually degraded).

Regarding high radiation flux tests. In general, $\Delta \rho$ suffered by the samples in this test is not significant, indicating no damage for the irradiation conditions applied. Only sample 9 showed a small reflectance loss $(\Delta \rho=0.014)$. According to the visual inspection, none of irradiated samples apart from sample 7 and 9 were affected, even after exposure to the highest radiation flux levels (see Table 5).

While after concentrated solar irradiation, almost no degradation of the reflectance value was observed, a few structural defects occurred. Sample 7 showed multiple cracks after the irradiation (see Fig. 17). These cracks were apparently originating from stress induced by screwing in the piping connectors far enough to make them water tight. This shows the importance of correct handling and gluing procedures of the mirrors on their support to avoid critical stresses during testing. In addition, radiation flux (or 

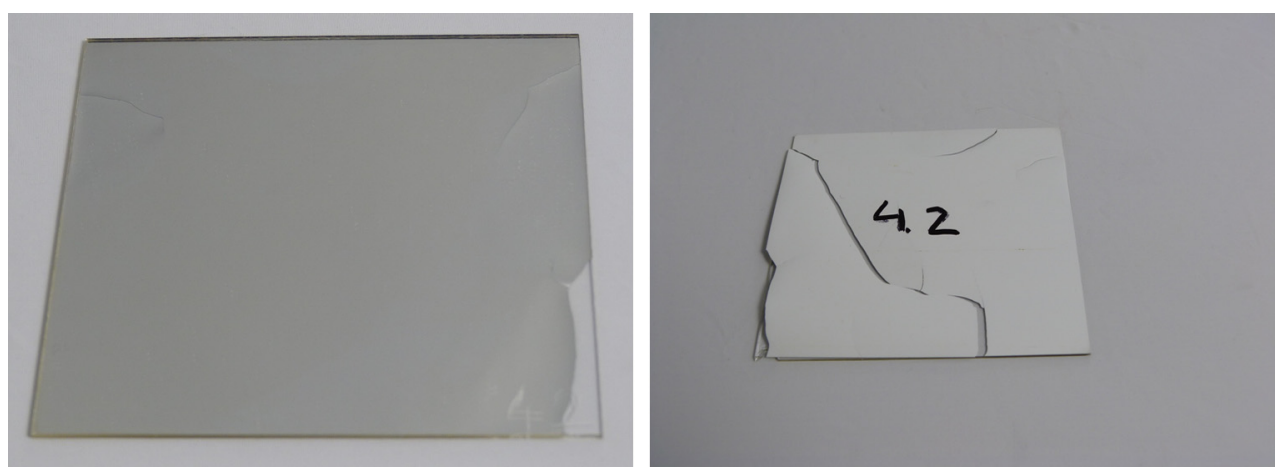

Fig. 12. Picture of front side (left) and back side (right) of sample 4, after the damp heat test.

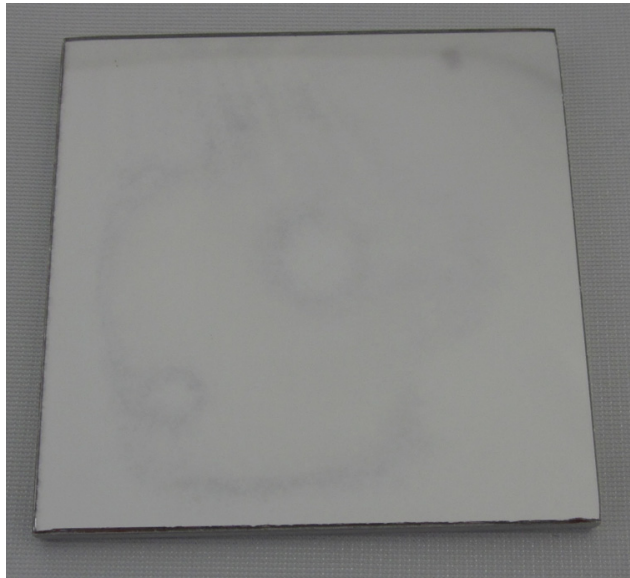

Fig. 13. Picture of sample 5 , after the humidity test.

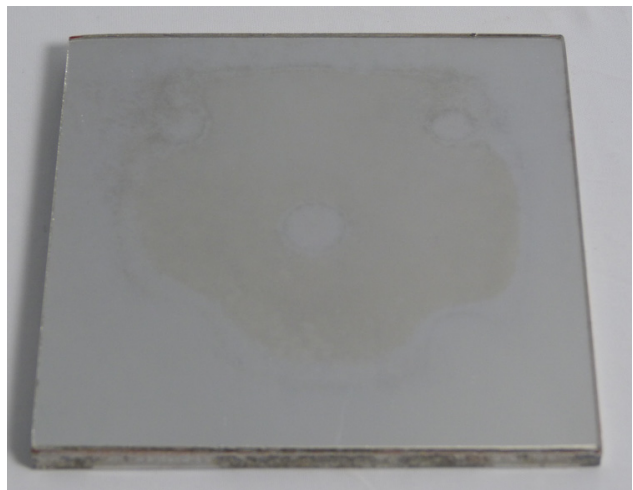

Fig. 14. Picture of sample 5, after the damp heat test.

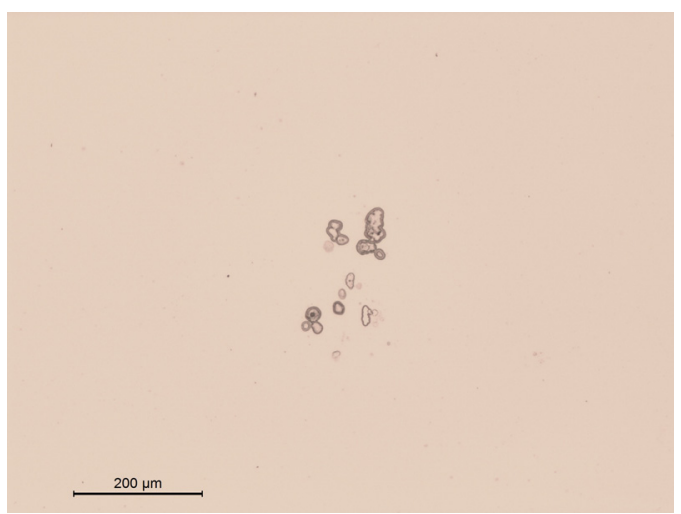

Fig. 15. Microscopic view of sample 5 degradation stain, after the damp heat test.

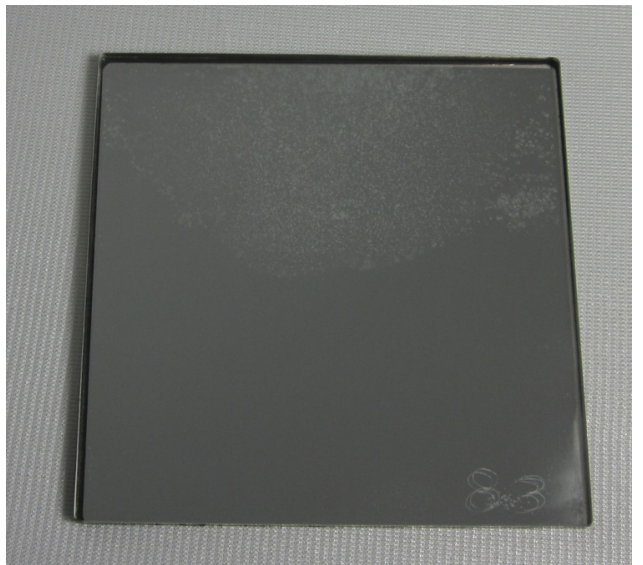

Fig. 16. Picture of sample 8 , after the humidity test.

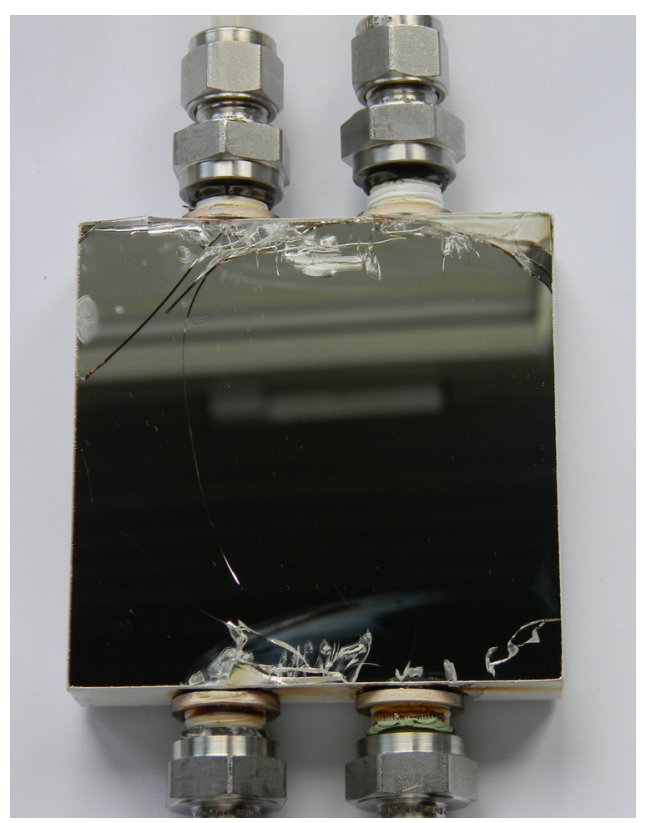

Fig. 17. Picture of sample 7, after high radiation flux test with $1470 \mathrm{~kW} / \mathrm{m}^{2}$.

mechanical stress induced by temperature gradients) probably helped the cracks to form or enlarge in the future. These temperature gradients are produced because samples are exposed to cooling from the internal side and a high radiation flux from the external side (something that does not occur in the temperature test, where temperature is homogeneously applied in the whole sample surface). In order to perform a deeper investigation of the 
phenomena detected in this test, a new testing campaign is under preparation to combine high flux radiation and weathering tests.

Sample 9 was seriously damaged during the 2 nd irradiation test at the highest planned flux of $291 \mathrm{~kW} / \mathrm{m}^{2}$ (see Fig. 18), which is a flux level far above the typical level in a 2D-CPC. Therefore, this failure shows a limit, but is not relevant for nowadays operating conditions.

\subsection{Natural aging}

Most of the secondary concentrator surface was in satisfactory conditions. However, after detailed visual inspection, several degradation evidences were observed in some specific regions, mainly near some edges or joints. The whole sample surface affected by defects in every single concentrator, SecNT1 and SecNT2, ranged around $5 \%$ of the total surface. This percentage was calculated through a visual estimation due to the difficulty involved in measuring the area affected by every single imperfection detected. More degraded reflector areas correspond in general to those that supported higher mechanical loads, withstood higher temperatures, was subjected to refrigeration system failures, and manipulation took place during installation and system adjustments. In future systems, these failures have to be avoided in order to maintain the quality of a secondary concentrator of this type. Typical degradation features detected are listed below:

(a) Edge silver corrosion. The most frequent degradation pattern is silver corrosion in the edges of the reflector segments. The area affected in this case is typically a line in the segment border with a width of up to $1 \mathrm{~cm}$. The number of segment edges affected by this kind of defect was counted. Considering the total number of segment edges that forms the concentrators, it was determined that the $35 \%$ of them was affected. In the inspection, it was observed that the edges suffered some adhesive material (glue or sealing) losses. It is reasonable to believe that the silver deterioration started in the same area where the adhesive material is lost. Therefore, the way to avoid this defect is to use a more resistant material to attach the different reflector segments among them. This deterioration seemed more aggressive in the down facing reflectors, located on the ceiling of the concentrator cavity and in the ones facing up according the horizontal concentrator axis, as shown in Fig. 19.

(b) Glass-cover breakage with inner silver corrosion. Some spots were detected with the corrosion starting at the center of the reflector segment and not at the edges. In this case, the size of the area affected by the silver corrosion is typically a circle of

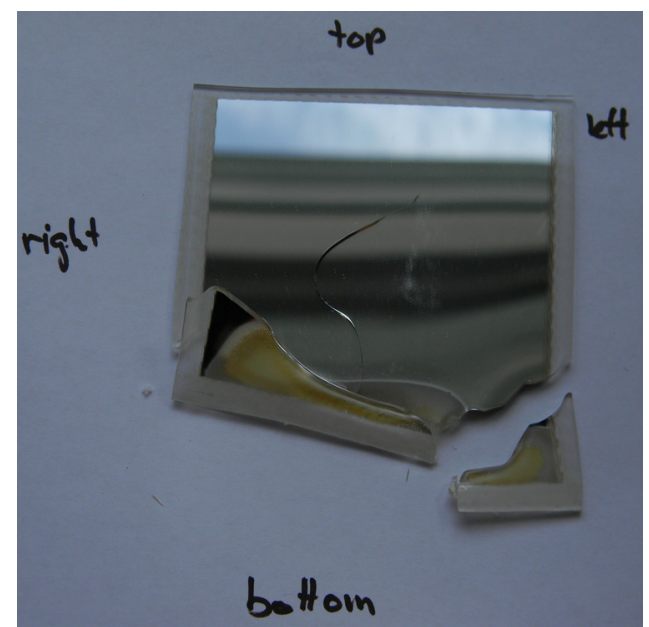

Fig. 18. Picture of sample 9, after high radiation flux test with $291 \mathrm{~kW} / \mathrm{m}^{2}$.

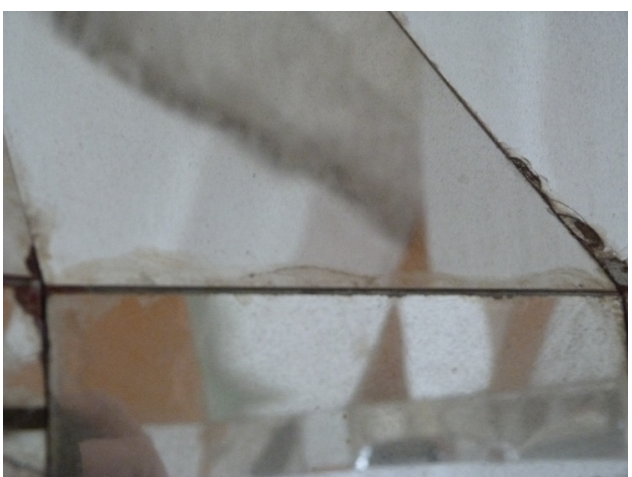

Fig. 19. Edge silver corrosion, after natural aging.

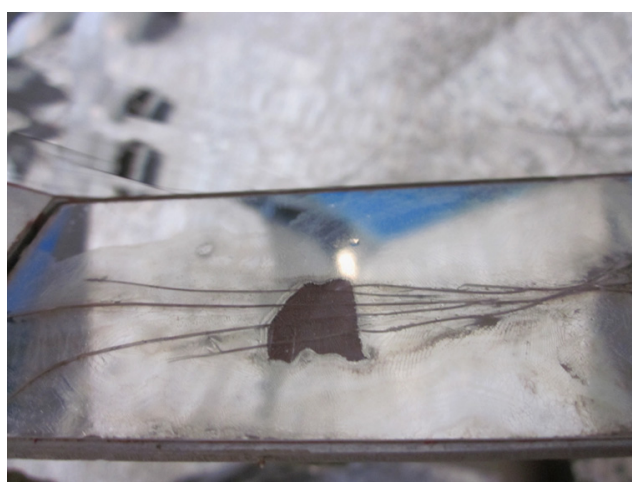

Fig. 20. Glass-cover breakage with inner silver corrosion, after natural aging.

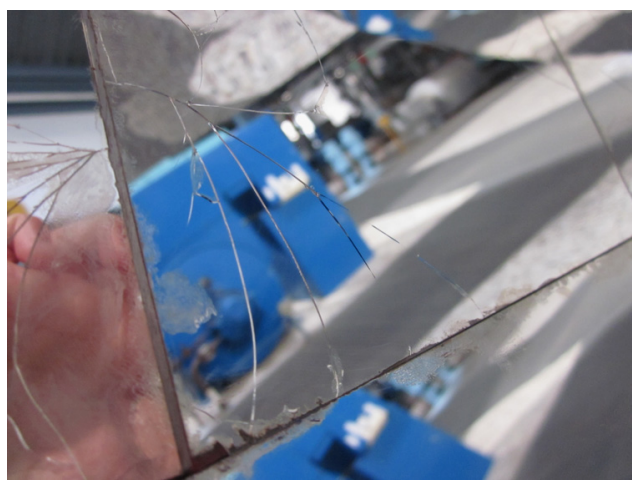

Fig. 21. Glass-cover breakage, after natural aging.

up to around $1.5-\mathrm{cm}$ diameter. The length of the glass-cover crack is variable, from some millimeters to $4 \mathrm{~cm}$. All the zones with this type of silver corrosion also present a glass-cover breakage. Therefore, the corrosion is probably caused by the previous top glass breakage and the later humidity penetration, as Fig. 20 shows. The most probable reason for the glass breakage is that the cooling system is insufficient and temperatures reached are too high. Another reason may be found in fissures made during system manipulation (manufacturing, installation or maintenance). Consequently, to avoid these defects, cooling systems must be carefully designed and mounted.

(c) Glass-cover breakage. As can be observed in Fig. 21, in this case the glass-cover breakage did not involve deterioration of the silver around it. One reason for not having silver corrosion could be that the glass breakage is not deep enough and has not reached the silver layer yet. 
(d) Glass-cover breakage with glass-cover losses and silver corrosion. This defect is the most extreme and the combination of the previous ones (Fig. 22). In this case, the glass-cover breakage evolved to a loss of glass and, as a consequence, the corrosion of the silver layer was complete.

(e) Back paint degradation. Deterioration of the back paint was observed in unprotected areas where the back painting is completely exposed or not assembled to any cooling system structure (see Fig. 23).

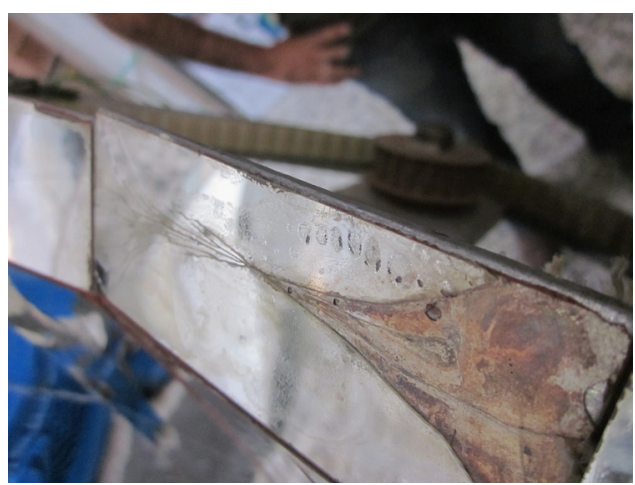

Fig. 22. Glass-cover breakage with glass-cover losses and silver corrosion, after natural aging.

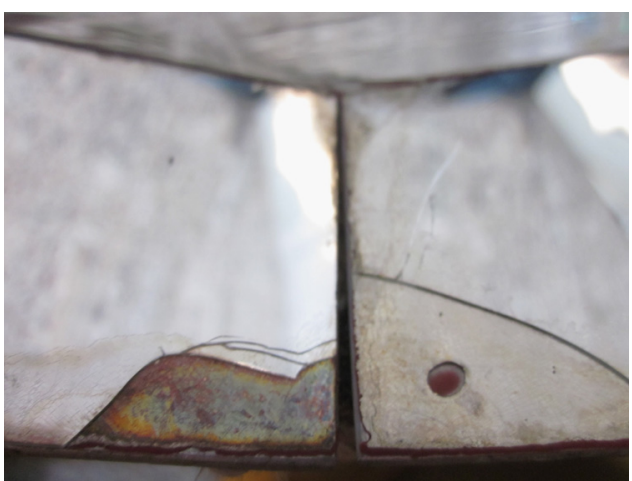

Fig. 23. Back paint degradation, after natural aging.

\subsection{Comparison between accelerated and natural aging}

Table 8 shows a comparison among the aging effects observed both in natural and accelerated aging tests. As secondary concentrator analyzed in the natural aging study is a 3D-CPC with thin silveredglass reflectors, only accelerated aging results of samples 2-7 are included in this comparison.

\section{Conclusions}

A complete set of accelerated aging tests for reflector material used in secondary concentrators (both cooled and uncooled) was specially designed and performed. Following main conclusions were acquired:

- In terms of degradation, aluminum reflectors showed an appropriate behavior for cooled 3D secondary concentrators. Using aluminum as reflector is particularly interesting because the cooling structure of the concentrator is typically made of it, as well, and, as a consequence, it will not suffer mechanical stress due to different dilatation coefficient, avoiding difficulties suffered by silver reflectors, such as glass cover breakages. On the contrary, the main disadvantage of this reflector material is that aluminum presents much lower initial reflectance (0.861) than silver which results in lower system efficiencies and higher thermal loads.

- Thin-glass silvered reflectors showed the highest values of initial reflectance (between 0.947 and 0.949) and demonstrated a good performance for cooled 3D secondary concentrators, without suffering significant reflectance losses in most of the cases. Degradation in the back paints close to the edges and chemical reaction between the reflector and the glue occurred in some cases, mainly after humidity and damp heat (high temperature and humidity) tests. In addition, glass breakages were suffered after the high radiation test when mechanical stress was applied. The important issues to take into consideration in this case are to select a suitable adhesive material and procedure to glue the thin silvered-glass reflector to the support aluminum structure, to properly protect reflectors edges, to design a proper cooling system and to avoid the combination of high radiation fluxes with mechanical stress.

- Concerning reflector material for uncooled 2D secondary concentrators, the examined sample of thick-glass silvered reflectors, sample code 8 , is not suitable because it showed

Table 8

Comparison between natural and accelerated aging tests.

\begin{tabular}{|c|c|c|}
\hline Aging effect & Natural aging & Accelerated aging \\
\hline Silver corrosion & $\begin{array}{l}\text { It is predominantly caused by weathering } \\
\text { Affects mostly to vulnerable or weak areas: edges (mainly without } \\
\text { protection), back unprotected areas and glass breakages }\end{array}$ & $\begin{array}{l}\text { Mainly caused after humidity and damp heat tests } \\
\text { Detected in general close to the edges and in samples } \\
\text { with weak or unprotected edges }\end{array}$ \\
\hline $\begin{array}{c}\text { Glass-cover } \\
\text { breakage }\end{array}$ & $\begin{array}{l}\text { It occurs principally due to mechanical stress, cooling system failure, } \\
\text { and during the handling and assembling processes } \\
\text { In some areas, it involves silver corrosion }\end{array}$ & $\begin{array}{l}\text { Occurred in samples } 7 \text { and } 9 \text { after the high radiation } \\
\text { flux tests (in combination with mechanical stress in } \\
\text { sample } 7 \text { ) }\end{array}$ \\
\hline $\begin{array}{l}\text { Back paint } \\
\text { degradation }\end{array}$ & $\begin{array}{l}\text { Observed in unprotected areas where the back painting is outdoor } \\
\text { exposed or not assembled to any cooling system structure }\end{array}$ & $\begin{array}{l}\text { It is observed after humidity test (samples } 2 \text { and } 3 \text { ) and } \\
\text { damp heat test (sample } 4 \text { ) } \\
\text { In some samples, the degradation entail silvered corrosion } \\
\text { and back paint losses }\end{array}$ \\
\hline $\begin{array}{l}\text { Edges protection loss } \\
\text { (or absence) }\end{array}$ & $\begin{array}{l}\text { It seems to be caused by extreme conditions exposure (i.e. high temperature and } \\
\text { humidity) and cooling system failure } \\
\text { Clearly related to silver corrosion close to edges }\end{array}$ & $\begin{array}{l}\text { It involves corrosion of the silver layer visible through } \\
\text { the glass-cover (sample 5) after humidity and damp } \\
\text { heat tests }\end{array}$ \\
\hline
\end{tabular}


unacceptable reflectance losses during the accelerated aging tests. The reason for this might be an insufficient protective back layer, not designed for the application of high temperatures. So this result must not be generalized. The laminated silvered-glass reflectors specially designed for high temperatures, sample code 9 , have shown to be a proper candidate. Although the laminated silvered-glass reflector presents intermediate values of initial specular solar-weighted reflectance (0.912), negligible reflectance losses were detected after several accelerated aging tests.

Furthermore, a comparison with naturally aged secondary concentrators revealed that the simulated degradation under accelerated conditions performed in this work did reproduce the most frequent degradation patterns suffered in real operating conditions. A thorough investigation with appropriate instruments is required for a better understanding of the degradation mechanisms occurred.

\section{Acknowledgments}

Financial support by the European Union under the 7th Framework Programme (SFERA Grant Agreement no. 228296) is gratefully acknowledged. The authors want to thank Thorsten Denk from CIEMAT for his help in the analysis of the naturally-aged secondary concentrators, Jens Jedamski from DLR for the preparation of same of the samples tested as well as Peter Schaller and Daniel Wuillemin from PSI for their help in the sample testing under high radiative flux. Authors also want to thank to Alanod for providing samples coded as number 1 in this document, and Guardian Solar for providing samples coded as number 9 in this document.

\section{References}

[1] D. Mills, Advances in solar thermal electricity technology, J. Sol. Energy 76 (2004) 19-31.

[2] H. Price, E. Lüpfert, D. Kearney, E. Zarza, G. Cohen, R. Gee, R. Mahoney, Advances in parabolic trough solar power technology, J. Sol. Energy Eng. 124 (2002) 109-117.

[3] A. Fernández-García, E. Zarza, L. Valenzuela, M. Pérez, Parabolic-trough solar collectors and their applications, Renew. Sustain. Energy Rev. 14 (2010) 1695-1721.

[4] A. Meier, A Steinfeld, Solar energy in thermochemical processing, in: R. A. Meyers (Ed.), Encyclopedia of Sustainability Science and Technology, Springer, 2012, pp. 9588-9619.

[5] Solar Thermal Electricity, Strategic Research Agenda 2020-2025, Brussels, December 2012

[6] A. Meier, C. Sattler, Solar Fuels from Concentrated Sunlight, IEA SolarPaces Implementing Agreement, Tabernas, 2009.
[7] H. Hinterberger, R. Winston, Rev. Sci. Instrum. 37 (1966) 1094.

[8] R. Winston, J.C. Minano, P. Benitez, Nonimaging Optics, Elsevier Academic Press, Amsterdam, 2005.

[9] A. Rabl, Optical and thermal properties of compound parabolic concentrators, Sol. Energy 18 (1976) 497-511.

[10] A. Yogev, A. Kribus, M. Epstein, A. Kogan, Solar tower reflector systems: a new approach for high temperature solar plants, Int. J. Hydrogen Energy 23 (1998) 239-245.

[11] A. Segal, M. Epstein, The optics of the solar tower reflector, Sol. Energy Suppl. 69 (2000) 229-241.

[12] C.E. Kennedy, K. Terwilliger, Optical durability of candidate solar reflectors, J. Sol. Energy Eng. 127 (2005) 262-268.

[13] F. Sutter, S. Ziegler, M. Schmuücker, P. Heller, R. Pitz-Paal, Modelling of optical durability of enhanced aluminum solar reflectors, J. Sol. Energy Mater. Sol. Cells 107 (2012) 37-45.

[14] R. Buck, T. Bräuning, T. Denk, M. Pfänder, P. Schwarzbözl, F. Tellez, Solar-hybrid gas turbine-based power tower systems (REFOS), J. Sol. Energy Eng. 124 (1) (2002) 2-9.

[15] M. Schmitz, P. Schwarzbözl, R. Buck, R. Pitz-Paal, Assessment of the potential improvement due to multiple apertures in central receiver systems with secondary concentrators, Sol. Energy 80 (2006) 111-120.

[16] European Commission, SOLGATE - solar hybrid gas turbine electric power system, Final Publishable Report, Contract ENK5-CT-2000-00333, 2006.

[17] ISO 9227, Corrosion tests in artificial atmospheres - Salt spray test, International Organization for Standardization, ISO, 2006.

[18] IEC 61215, Crystalline silicon terrestrial photovoltaic (pv) modules - design qualification and type approval, International Electrotechnical Commission, IEC, 2005.

[19] ISO 6270-2, Paints and varnishes - Determination of resistance to humidity Part 2: Procedure for exposing test specimens in condensation-water atmospheres, International Organization for Standardization, ISO, 2005.

[20] C. Hutter, C. Wieckert, A. Fernández-García, Thermal testing of solar mirrors for secondary concentrators (SFERA Work Package 13, Task 2, Subtask Hardware), Technical Report, PSI, Switzerland, 2011. Available at: 〈http://sfera. sollab.eu/downloads/JRA/WP13/R13.5a_SFERA_WP13_T2B_Report_thermal_t ests.pdf .

[21] J. Petrasch, P. Coray, A. Meier, M. Brack, P. Haeberling, D. Wuillemin, A. Steinfeld, A 50-kW 11,000-suns novel high-flux solar simulator based on an array of Xenon arc lamps, J. Sol. Energy Eng. 129 (2007) 405-411.

[22] S. Meyen et al., Parameters and method to evaluate the solar reflectance properties of reflector materials for concentrating solar power technology SolarPACES Reflectance Guideline actual version 2.5, Almería, June 2013. Available at: 〈http://www.solarpaces.org/〉 Tasks/Task3/reflectance_guideline. htm.

[23] S. Meyen, A. Fernández-García, C. Kennedy, E. Lüpfert, Standardization of solar reflector reflectance measurements - round robin test, SolarPACES 2010, Perpignan, September, 2010, pp. 21-24.

[24] Devices and Services, Portable Specular Reflectometer Model 15R-USB. Operation and Maintenance Manual, Devices and Services, Dallas, 2009.

[25] J.L. Taylor, Reflectance Measurements of Materials Used in Solar Industry, Perkin-Elmer, Shelton, 2009.

[26] ISO 9050, Glass in building - determination of light transmittance, solar direct transmittance, total solar energy transmittance, ultraviolet transmittance and related glazing factors, International Organization for Standardization, ISO, 2003.

[27] ASTM G173-03: 2003. Standard Tables for Reference Solar Spectral Irradiances: Direct Normal and Hemispherical on $37^{\circ}$ Tilted Surface, American Society for Testing and Materials, ASTM, 2003.

[28] 3D light microscope by ZEISS, Axio CSM 700 Operating Manual, Carl Zeiss Microlmaging GmbH., Jena, 2010. 